\section{International Journal \\ of \\ English Studies}

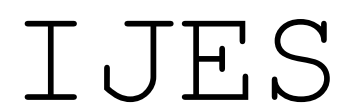

http://revistas.um.es/ijes

\title{
Complementary alternation discourse constructions in English: A preliminary study ${ }^{1}$
}

\author{
ANEIDER IZA ERVITI * \\ Universidad de La Rioja
}

Received: 19/03/2014. Accepted: 24/10/2014.

\begin{abstract}
This paper examines the essential features of a group of constructions that belong to the family of complementary alternation discourse constructions in English. In this group of constructions, $\mathrm{X}$ and $\mathrm{Y}$ are two situations such that $\mathrm{Y}$ is less likely (or more likely) to happen than $\mathrm{X}$. Each member of this group (X Let Alone Y, X Much Less Y, X Never Mind Y, X Not To Mention Y, Not X Nor Y, X Still Less Y, Not X Not Even Y, and $\mathrm{X}$ To Say Nothing of $\mathrm{Y}$ ) introduces subtle changes in focal structure, resulting in changes on the overall coherence of the text. Based on these theoretical explanations, the paper specifies the conditions for the use of one connector with preference over the others. Finally, the paper argues that in these constructions we find two types of cognitive operations at work: simple cognitive operations (negative addition and/or re-association) and operation amalgams, which combine different cognitive operations.
\end{abstract}

KEYWORDS: complementary alternation, discourse, constructions, LCM, cognitive operation.

\section{RESUMEN}

Este artículo examina las características esenciales de un grupo de construcciones dentro de la familia de construcciones discursivas de alternancia complementaria en inglés. En dicha familia, X e Y son dos situaciones en las que $Y$ es menos probable (o más probable) que suceda que $X$. Cada miembro de esta familia construccional (X Let Alone Y, X Much Less Y, X Never Mind Y, X Not To Mention Y, Not X Nor Y, X Still Less $Y$, Not X Not Even Y, y X To Say Nothing of Y) introduce sutiles cambios de significado, lo cual cambia la coherencia global del texto. Basándose en estas explicaciones teóricas, el artículo especifica las condiciones de preferencia de uso de un conector sobre los demás. Por último, el artículo sostiene que en relación a estas construcciones encontramos dos tipos de operaciones cognitivas: operaciones cognitivas simples (suma negativa y/o re-asociación) y amalgamas de operaciones, que combinan diferentes operaciones cognitivas.

PALABRAS CLAVE: alternancia complementaria, discurso, construcciones, LCM, operaciones cognitivas.

*Address for correspondence: Aneider Iza Erviti. Departamento de Filologías Modernas, Universidad de la Rioja, C/ San José de Calasanz s/n, 26004 Logroño (La Rioja), Spain; e-mail: aneider.izae@unirioja.es. 


\section{INTRODUCTION}

The present paper offers the reader a preliminary analysis of a set of related discourse constructions, which fall under the umbrella of the so-called complementary alternation relations (cf. Mairal \& Ruiz de Mendoza, 2009: 176). Such relations have been programmatically posited by Mairal and Ruiz de Mendoza (2009) as underlying a family of discourse constructions. The notion of "family," which has been extensively used as an organizing factor in the domain of lexical meaning, has also been used productively to account for similarities and differences among non-lexical constructions, i.e. entrenched formmeaning pairings of whatever complexity at any descriptive level. For example, GonzálvezGarcía $(2009 ; 2012)$ has used the notion of family resemblance to carry out a detailed analysis of object-related depictives involving verba cogitandi (e.g. I find her so sweet, He considers you a friend, We all thought him dead), Goldberg and Jackendoff (2004) for the many kinds of resultative constructions (e.g. She shot him dead, He molded clay into a bird, She kicked him black and blue), and Del Campo $(2011 ; 2013)$ for a broad variety of illocutionary constructions (e.g. Will you help me?, Help me, will you?, Do you think you could help me?, etc.).

According to Mairal and Ruiz de Mendoza (2009), complementary alternation constructions are to be distinguished from contrastive alternation constructions. In the latter (e.g. Either you win or you lose), two alternates are presented as being antithetical. By contrast, in the former the alternates are not exclusive of each other (e.g. No one insulted him nor did physical harm to him). This view of complementary alternation relations is in need of a more precise definition. According to Mairal and Ruiz de Mendoza (2009), the concept of complementary alternation is to be understood in paradigmatic contrast with other semantic extension relations such as meaning addition (She is an excellent mother and a good neighbour too) and meaning exception (He believes there is no genius other than himself). This is only partially correct. The complementary alternation has a clear additive ingredient where the assumption expressed by one of the alternates is endowed with greater strength (thus receiving focal prominence) than the other. This can happen in two ways. In one, the alternates negate what the speaker believes are someone's assumptions (e.g. I would never date, let alone marry, someone as rude as you). In the other, the alternates are positive (e.g. I always cry watching sad films, let alone reading their scripts) and simply add information where the second alternate is more emphatic than the first. Furthermore, in the first situation, the first and second alternate are in a logical cause-consequence relationship where, if the first were the case, that would open the door for the second to be possible. Negating the first logically precludes the second from ever taking place.

These uses are marked by such connectors as let alone, much less, even less, never mind, not to mention, and to say nothing of and can be considered to structure a special group of constructions within the complementary alternation family. Dictionaries ${ }^{2}$ usually treat 
some of these connectors as largely equivalent and indeed they can be interchangeable: No one insulted him, let alone/much less/still less did physical harm to him; She has produced an amazing musical project, not to mention/to say nothing of her new DVD. However, here there are uses of these connectors where they are not necessarily interchangeable. The present article offers the reader preliminary work identifying such uses and determines relevant meaning differences among them. This allows us to arrange them, as suggested above, on the basis of family resemblance relations (cf. Taylor, 1995).

In order to discuss the group of complementary alternation constructions selected above, the present study will make use of the Lexical Constructional Model, or LCM, as propounded by Ruiz de Mendoza and Mairal (2008, 2011), Mairal and Ruiz de Mendoza (2009), Ruiz de Mendoza (2013), and Ruiz de Mendoza and Galera (2014) (cf. Butler 2009, 2013, for in-depth critical overviews). The LCM is a usage-based, comprehensive theory of meaning construction that combines insights from cognitive, functional and pragmatic approaches to language. The model allows for the investigation of meaning construction at four levels of linguistic description: argument structure (level 1), implicational structure (level 2), illocutionary structure (level 3) and discourse structure (level 4). The different levels interact among one another following a number of conceptual compatibility and construal principles.

Three features of the LCM are useful to deal with constructional behaviour in general and with complementary alternation discourse constructions in particular:

(1) Its ability to see structure in terms of its function, like functionalist approaches to language, while searching for such motivation in the domain of communicative activity and in the domain of cognition.

(2) Its understanding of the notion of construction as ranging from argument structure characterizations via implicational and illocutionary representations to discourse structure. The LCM further defines a construction not only as a form-meaning paring, as Goldberg $(1995,2006)$ does, but, in a more refined way, as a conceptually entrenched (i.e. frequent and straightforwardly replicable) formmeaning association where form is realizational of conceptual representation in any degree of complexity (cf. Ruiz de Mendoza, 2013: 238). ${ }^{3}$

(3) The admission that, more often than not, constructions come in families of related conceptual configurations that offer speakers a gamut of meaning choices.

Most of the work carried out in the LCM has taken place at the levels of argument structure (cf. Peña, 2009; Baicchi, 2011; Galera \& Ruiz de Mendoza, 2012; Ruiz de Mendoza \& Mairal, 2011; Ruiz de Mendoza, 2013; and the references therein) and illocution (cf. Ruiz de Mendoza \& Baicchi 2007; Baicchi \& Ruiz de Mendoza 2010; Del Campo, 2011; Del Campo, 2013; Pérez \& Ruiz de Mendoza, 2011; Ruiz de Mendoza \& Gonzálvez-García 2011; 
and the references therein). Implicational and discourse structure are still at a programmatic stage, with only partial work carried out in Ruiz de Mendoza and Mairal (2008), Mairal and Ruiz de Mendoza (2009) and Ruiz de Mendoza (2013), for both levels, and Ruiz de Mendoza and Gómez González (2014), which address only general taxonomic aspects and suggest the possibility of organizing discourse constructions on the basis of family resemblances. Ruiz de Mendoza and Galera (2014) have offered a broad overview of constructions at all descriptive levels from the point of view of the kinds of cognitive structure underlying them. However, the authors have not made any exhaustive account in terms of families. It is therefore necessary to further develop these initial explorations in order to endow the LCM with greater discourse adequacy. This paper will undertake this task by discussing the complementary alternation constructional family, whose members share a basic discourse function: one of two negative propositions, which are formally presented as alternates, adds to the other (Mairal \& Ruiz de Mendoza, 2009: 29).

The structure of this paper is as follows. The following section will define the notion of complementary alternation as a basic discourse relation and will discuss the way in which constructions exploit such a relation. The discussion will be based on the application of the Langackerian notions of profile/base relations and the selection of active zones within profiled concepts (cf. Langacker, 1987, 1999). The paper argues that such constructs are applicable not only to lexical structure but also to other kinds of conceptual structure including discourse relations. Finally, the paper will provide the reader with preliminary conclusions on the role of constructions and constructional families in discourse structure and it will point out some of the advantages of the account offered herein over Fillmore et al.'s (1988) well-known discussion of the let alone construction.

\section{THE NOTION OF CONSTRUCTION}

Central to the present paper is the notion of construction. The original definition of construction is found in Goldberg's work: " $\mathrm{C}$ is a CONSTRUCTION iff def $\mathrm{n}$ is a formfunction pair, such that some aspect of the form or some aspect of the function is not strictly predictable from C's component parts" (Goldberg, 1998: 205).

On the basis of this definition, we can ascribe constructional status to idiomatic expressions (He let the cat out of the bag), lexical items, and even morphemes, since their meaning cannot be predicted from their form. But the emphasis is on the non-compositional nature of constructions. For example, the meaning of a transitive sentence can be obtained by summing up the meaning of its parts (e.g. The cat killed the mouse, where 'kill' is defined as 'cause to become dead' so that the sentence is interpreted as 'The cat caused the mouse to become dead'). However, this is not the case with other morphosyntactic configurations. The ditransitive construction provides some illustration. In Pat faxed Bill the letter we understand that Pat caused Bill to receive a copy of the letter that was electronically transmitted from one 
fax machine to another. However, the verb fax 'transmit printed matter by electronic means' does not necessarily involve a recipient. This element is supplied non-compositionally by the construction.

The non-compositionality criterion was also central to work by Fillmore and his associates (see Kay, 2002). For example, WXDY (What's X Doing Y? What's the dog doing sleeping in the bed?), studied by Kay and Fillmore (1999) is non-compositional. The construction conveys the speaker's annoyance at a situation about which he is not really asking. This meaning is not predictable from its component parts. In fact, from a strict compositional perspective, $W X D Y$ would be an information question, which is generally not the case in this kind of configuration. However, other scholars have argued that frequent configurations (or "symbolic assemblies" of form and meaning) are constructions even if they are fully compositional (e.g. Langacker, 2005). This is a position that Goldberg herself has adopted (cf. Goldberg, 2006: 5). In this position, again following Langackerian postulates (cf. Langacker, 1999: 105), constructions are "entrenched" associations of form and meaning. The notion of "entrenchment" is but the cognitive correlate of the classical notion of "conventionalization", commonly used in functional linguistics. But the notion of conventionalization, which involves frequent use, is based on the social acceptance of a construction as such rather than on its cognitive reality.

The obvious problem with the frequency criterion is that it is too vague. How many uses of a form-meaning pairing are necessary to postulate a construction? What is the threshold point and what criteria are necessary to set it up? Since the related notions of entrenchment and conventionalization somehow arise from an explicit or an implicit acceptance of frequency of use, these notions are also theoretically weak. One interesting proposal is found in the LCM, which postulates "replicability" as a viable criterion. According to Ruiz de Mendoza (2013), frequency (together with its associated concepts of entrenchment and conventionalization) is a potential side-effect of a deeper phenomenon that concerns what competent native speakers of a language regard as well formed and highly natural linguistic output. Such natural output, in fact, is not only regarded as such, but it is also potentially replicable by other speakers of the language. At any time, a given form-meaning pairing may be replicated by other competent speakers of a language thus becoming frequent and, possibly, cognitively entrenched and socially conventional.

This approach to the concept of construction is important for the present study of complementary alternation constructions. We have chosen to disregard the frequency criterion as relevant to setting up the family of complementary alternation constructions. Any potentially replicable form-meaning pairing that sets up a complementary alternation where one of the alternates is presented as less likely than the other is a candidate for our study. 


\section{A NOTE ON METHODOLOGY}

The cognitive-linguistic literature on discourse constructions is very limited and, as we mentioned above, in serious need of exhaustive explorations. The best known case study is found in Fillmore et al. (1988), which provides a detailed analysis of the Let Alone construction, but without considering its discourse dimension. The treatment in the LCM of the same construction (e.g. Mairal \& Ruiz de Mendoza, 2009; Ruiz de Mendoza \& Gómez González, 2014) is programmatic too and simply limited to inserting the construction within a broad typological framework of discourse constructions. An important pending task, which the present paper aims to deal with, is to identify and group constructions within a given domain (in the present case a subset of complementary alternation constructions) on the basis of similarities and differences among them. Here, we will motivate the use of a group of related constructions in terms of relevant theoretical postulates from cognitively-oriented constructionist approaches to language, especially the Goldbergian strand including some of its developments in the LCM.

The present study is based on real examples mainly extracted from extensive corpus searches within the Contemporary Corpus of American English (http://corpus.byu.edu/coca/), which have been occasionally complemented with examples from the British National Corpus (accessed at http://www.natcorp.ox.ac.uk/) and the WebCorp or even dictionaries and the previous literature on the topic. These corpora were chosen on the basis of their size and their representativeness. Our intention was to count on as many duly contextualized occurrences as possible of complementary alternation markers, with a view to determining their degree of synonymy. It must be borne in mind that most dictionaries, and the usage examples they supply, tend to treat many of such markers as fully synonymous. However, as our later analysis will reveal, this is not necessarily the case. There follows a brief summary of our steps of analysis.

Our starting point was a thorough examination of the literature on the Let Alone construction, which allowed us to list its central semantic and formal features. Then, we looked for connectors that relate to let alone by looking for synonyms in a number of dictionaries: Collins Cobuild Dictionary (1990), Merriam Webster Dictionary Online, Cambridge Dictionary Online, Dictionary.com (http://dictionary.reference.com), and Wordreference (http://www.wordreference.com/). The next step was to compare definitions and use examples as provided by dictionaries. The definitions listed many of the connectors as fully interchangeable. However, even preliminary small-scale searches (of not more than 50 occurrences) in the corpora listed above showed that such fully synonymy was not the case. For some contexts, one connector was productive while others either did not occur or, if they occurred, they did with slightly different meanings. This observation led into considering the possibility of applying the Langackerian notion of active zones within a given profile (or designatum) to actually explain the subtleties of meaning of what could in essence be 
regarded as the same conceptual construct. Broader corpus searches (ranging between 100200 occurrences) confirmed the need to identify specific active zones within the various meaning profiles arising from each connector. At this stage it was necessary to find ways to explore whether a connector was a better choice than another for a given usage context. One way to do that was by manipulating examples by changing part of their formal configuration, then observing if such manipulation still yielded a correct linguistic expression. We made sure that the constructional change thus obtained was possible by looking for the same pattern in our corpora. Finding the same formal patterns carrying comparable meaning implications was a guarantee of having produced a viable constructional variant (a different active zone for the same profile). This technique allowed us to come across interesting constructional variants. For example, changing the polarity of part of Not X Nor Y (I won't drink that wine, nor pay for it) to $X$ nor $Y(* I$ will drink that wine, nor pay for it) resulted in an unacceptable pattern. However, when applying this polarity change to other constructions (e.g. X Let Alone $Y, X$ Never Mind $Y, X$ To say Nothing of $Y$ ), it became evident that it was possible and that it had different meaning consequences. For example, the interpretation of the sentence I always cry watching sad films, let alone reading their scripts is not so much a question of one action making it more likely for the speaker to cry as one of such an action intensifying the speaker's crying. However, I never cry watching sad films, let alone reading their scripts treats reading sad film scripts as less likely to make the speaker cry than watching them. What in the negative-polarity example is less likely to cause the speaker to cry (reading the scripts) is what in the positive-polarity example intensifies the speaker's crying. This characteristic of the positive-polarity examples blocks the use of much less (*I always cry watching sad films, much less reading their scripts), while it is possible in its negative counterpart (I never cry watching sad films, much less reading their scripts).

\section{COMPLEMENTARY ALTERNATION CONSTRUCTIONS}

The most neutral member of the complementary alternation family is the Not $X$ Nor $Y$ construction. This construction has two possible interpretations. One is obtained compositionally and the other non-compositionally. In its compositional interpretation, the construction simply adds a negative proposition $\mathrm{Y}$ to an equally negative (and conceptually related) proposition X (e.g. He has not resigned, nor has he been sacked ${ }^{4}$ ). In its noncompositional interpretation, there is an extra element conveying the speaker's incrementally negative stance towards the events or situation depicted in both propositions. For example, in I won't drink that wine, nor pay for $i t^{5}$, the idea that the speaker is not willing to drink a certain type of wine is complemented with the idea that he is also unwilling to pay for it. In some contexts, and with the cooperation of stress prominence on the second clause, the overall meaning result of this operation is one of intensifying the speaker's negative attitude about dealing with the wine. This non-compositional interpretation has been 
conventionalized, with different shades of meaning, by such configurations as $X$ Let Alone $Y$, $X$ Much Less $Y$, X Never Mind Y, X Not To Mention Y, and so on. Only the $X$ Let Alone $Y$ construction has been received in-depth treatment in the literature (cf. Fillmore et al., 1988). But extensive corpus evidence shows that the other constructions belong to the same constructional family and that there are subtle differences in meaning and contexts of use for each marker.

Additionally, the same corpus evidence shows that these constructions can be grouped in terms of family resemblance relations, as Gonzálvez-García (2009) has done in relation to constructional families at the level of argument structure. We postulate that if constructions have the same underlying discourse relation, we can group them under the same constructional family based on the resemblance connections that hold among them. Thus, $X$ Let Alone Y, X Much Less Y, X Still Less Y, X Never Mind Y, X Even Less Y, X Not To Mention $Y$, and $X$ To Say Nothing of $Y$ can be grouped into the same constructional family as can be seen in Table 1 below, because they all designate the same relation in the world: a complementary alternation according to which $\mathrm{X}$ and $\mathrm{Y}$ are not mutually exclusive of each other.

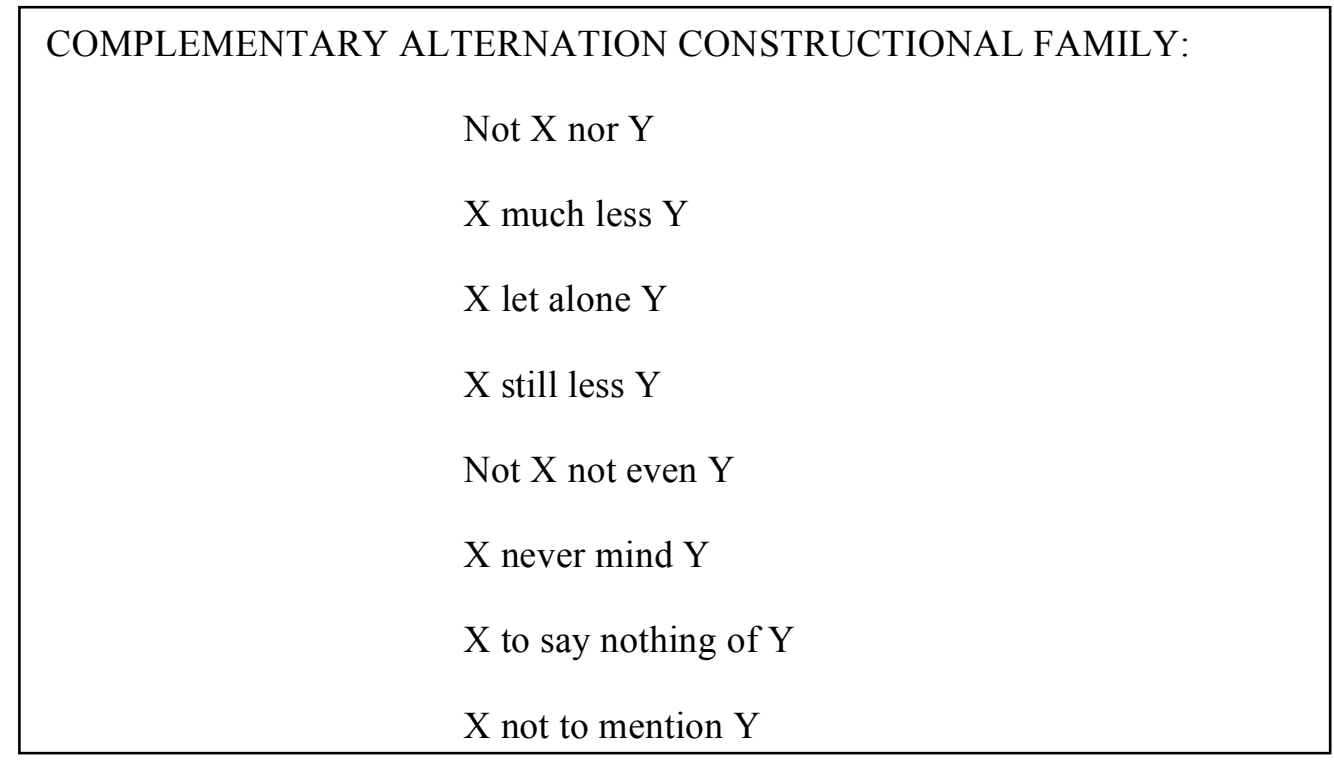

Table 1. Complementary alternation constructional family

However, these constructions differ from one another in subtle ways. In order to show how they differ, the present analysis will make use of Langacker's $(1987,1999)$ by now classical notions of base, profile and active zones. These notions will allow us to provide a comprehensive and fine-grained description of the linguistic behavior of complementary alternation constructions at discourse level.

As is well known, for Langacker concepts are understood in terms of profile/base relationships. The profile of a concept is whatever it designates. For example, the profile of 
'table' is a piece of furniture that has a flat top and usually one to four legs. But the concept 'table' can be viewed (or profiled) differently if you think of a table in the context of carpentry, an office or a kitchen.

Within the context of the base/profile distinction, Langacker introduces the notion of active zone within a profile, a relevant part of a meaning characterization with respect to a domain or relation. For example, the word table in I saw the table and Termites infested the table profiles (or designates) the same entity (a table, whether in a kitchen, an office or in the carpenter's workshop), but it is interpreted in terms of different active zones: the visible aspects of the entity in terms of size, shape, color, etc., on the one hand, and the non-visible wooden matter that the termites feed on, on the other hand.

For every conceptual characterization, whether high or low-level, we can postulate the existence of profile/base relations and of active zones (or relevant meaning facets) within profiles. Del Campo (2011) has cogently made this point for the case of illocutionary constructions. For example, the illocutionary construction How About X? designates (i.e. profiles) a proposal for action within the context (i.e. base domain) of the cost-benefit cognitive model, which captures the social convention that stipulates that we have to do our best to benefit other people even if this involves a cost to us (Ruiz de Mendoza \& Baicchi, 2007; Baicchi \& Ruiz de Mendoza, 2010). This proposal for action can have at least two different active zones each of which underlies a different illocutionary interpretation. In one, which gives rise to suggestions (e.g. How about buying another car?), the speaker puts forward a good option that may benefit the addressee; in the other, which results in invitations (e.g. How about coming and seeing my apartment?), the speaker asks the addressee to join him in a common course of action that will benefit both of them although in different ways (the addressee is expected to be benefitted by taking part in the action, while the speaker's benefit is derived from the positive feelings originating in social acceptance).

Discourse constructions naturally follow the same pattern of conceptual organization as lexical and illocutionary structure. Let us take the case of the contrast between the following constructions: Not X Let Alone Y, Not X Never Mind Y, Not X Still Less $Y$ and the Not X Much Less $Y$. All of them profile (i.e. designate) the same relation in the world: a complementary alternation according to which $\mathrm{X}$ and $\mathrm{Y}$ are two situations such that $\mathrm{Y}$ is less likely to happen than X (Mairal \& Ruiz de Mendoza, 2009). The base domain for this profiled relation is the same: a complementary alternation, i.e. a mutually non-exclusive (or additive) choice. However, these constructions make use of different active zones, each corresponding to a different meaning nuance. Let alone and never mind allow the $\mathrm{X}$ part of the construction to be positive in the $X$ Let Alone $Y$ and $X$ Never Mind $Y$ constructions, profiling the resulting meaning of $\mathrm{Y}$ being more likely to happen than $\mathrm{X}$. On the contrary, much less and still less do not allow their $\mathrm{X}$ parts to be positive. This is so due to the inherently negative axiology arising from our common experience of regarding small amounts as less beneficial than large amounts. This endows the adverb less with an axiologically negative shade of meaning, which 
explains the impossibility of finding a context where much less and still less are used positively. Therefore, $X$ Let Alone $Y$ and $X$ Never Mind $Y$ have a wider active zone than $X$ Much Less $Y$ or $X$ Still Less $Y$, as they allow the X part of the construction to be either positive or negative. But the speaker's preference to use a connector over another in a given context resides on the way let alone, never mind, still less and much less work on the notion of negative addition. Let alone and never mind do this by drawing our attention to the idea that whatever $\mathrm{Y}$ adds to $\mathrm{X}$ is specifically set apart as unique. By way of contrast, much less and still less focus on the possibility of going up or down on a scale of probability (a situation in question might be more or less probable). Let alone or never mind are neutral as to the existence of such a scale of probability. Consider the contrast between the examples (1) and (2) below:

(1) It is impossible to change the way Australians think about poverty, let alone/never mind/much less extreme poverty.

(2) How do you change the way Australians think about poverty, let alone/never mind ${ }^{*}$ much less extreme poverty? ${ }^{6}$

In example (1) the use of impossible is hyperbolic. It communicates the high unlikelihood (but not necessarily the impossibility) of Australians changing their approach to poverty. As is well known, hyperbole is used both for reasons of showing speaker's attitude and for enhanced impact on the addressee (cf. Ruiz de Mendoza, 2014). There is, therefore, a scale of probability involved where changing the way Australians think might be regarded as more or less probable, which licenses the use of much less (remember the neutrality of let alone and never mind with respect to probability noted above). In example (2), by contrast, we have two possible readings. In one of them, the speaker presupposes through a rhetorical question that it is not possible to change Australians' minds on the issue of poverty. In the other, we can have a mere information question about how to change their views. Whichever the interpretation, much less is inconsistent with the initial question. In the first scenario, based on a rhetorical question, the probability scale has been neutralized (i.e. there is no way the speaker will admit that there is any degree of probability). In the second scenario, there is simply neither explicit nor implicit mention of probability. This situation rules out the use of much less or still less, which require an active scale of probability. This is also attested in the following example:

(3) I always cry watching sad films, let alone/never mind /*much less reading their scripts. ${ }^{7}$ 
In this sentence the speaker separates specifically the idea of reading the scripts from watching the film, instead of concentrating on the possibility of crying more or less in one situation or another, which precludes the use of much less or still less.

Now, even though the $X$ Much Less $Y$ and $X$ Still Less $Y$ constructions are apparently synonymous, each of these two configurations exploits a different cognitive model, which results in subtle differences in their meaning. To begin with, consider the following examples:

(4) She was not going to betray it to the rest of the servants, still less to this intrusive policeman. (COCA, 1990).

(5) Any future, much less a secure one, seems hardly possible. (COCA, 2011).

Both constructions (X Much Less $Y$ and X Still Less $Y$ ) revolve around the idea of going up and down the scale of probability (the event $\mathrm{X}$ is not probable to happen and the event $\mathrm{Y}$ is less probable to happen than $\mathrm{X}$ ), but they use different routes to construct what appears to be the same meaning. In the case of $X$ Much Less $Y$, we use quantity adverbs to signal a decrease in the degree of probability of the event in question, i.e. $\mathrm{X}$ is a point on the scale of probability and $\mathrm{Y}$ is lower on the same scale (see Figure 1 below). This use of quantity to signal likelihood has an experiential grounding since greater quantities of objects or of a substance often correlate with the greater likelihood that the objects or the substance will be noticeable. Greater quantities of a substance or of objects also correlate with greater height. For example, when we pour water into a container, we see the level rise as we add more water. Within Cognitive Linguistics Lakoff and Johnson (1999) have postulated comparable correlations in other domains and psycholinguists like Gibbs $(2006 ; 2011)$ have provided empirical evidence in favor of experiential correlation leading to the conflation of different concepts in the mind. According to the evidence, conceptual conflation is the reason behind speakers using initially disparate concepts as if they were the same, as in Prices are soaring where soaring involves an increase in quantity, or in using much less to assess probability.

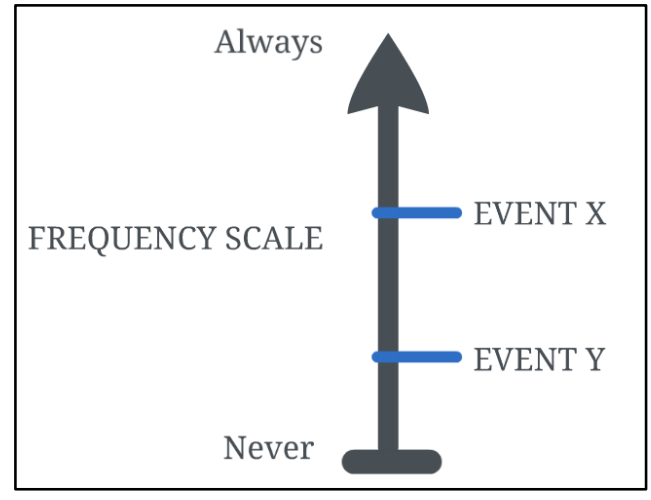

Figure 1. X Much Less $Y$ 
The value of $X$ Still Less $Y$ also makes use of the quantity-probability correlation mentioned above. However, the contrast between the likelihood of $\mathrm{X}$ and $\mathrm{Y}$ being the case is here marked directly by the use of still, which has inherent contrastive value arising from its original temporal meaning 'up to or at a specified time'. The nature of the likelihood of $Y$ is thus explicitly contrasted with the nature of the likelihood of X. This way of marking the probability contrast is evidenced by the following examples:

(6) The object is not to work hard, still less to make yourself miserable. The object is to get the work done. (COCA, 1996).

(7) We have to show that our values are not Western, still less American or AngloSaxon, but values in the common ownership of humanity. (COCA, 1996).

It is also necessary to note that in terms of active zone processes, there is a significant difference between the $X$ Much Less $Y$ and the $X$ Still Less $Y$ constructions. This difference is revealed by the slight oddity of using still less in (8a), versus the full adequacy of much less (8b.), which we have constructed for the sake of contrast:

(8) a. You cannot teach 400 students at a time, ?still less 100,000.

b. You cannot teach 400 students at a time, much less 100,000.

This happens because much less is sensitive to contexts that require a greater distance between the two alternates than still less when situating assertions on a scale. In (8a) and (8b) still less situates the proposition 'You cannot teach 400 students at a time' at any random point below the proposition 'You cannot teach 100,000 students at a time' on the scale of probability, whereas much less explicitly signals the existence of a greater distance between the two alternates on the same scale of probability. This is more consistent with the meaning arising from the linguistic context in which the construction is being used.

Finally, consider $X$ Never Mind $Y$. The rationale behind this construction is the implication that $\mathrm{X}$ is difficult to happen, but $\mathrm{Y}$ is less likely to happen than $\mathrm{X}$, which is why $\mathrm{Y}$ is not to be regarded.

(9) Adrià is a legend in the restaurant world, though most of humanity will never see, never mind taste, his food. (COCA, 2011).

(10) With this knee I can hardly walk, never mind run. (Merriam Webster Dictionary Online).

Our data reveal that although the members of this constructional family are generally regarded as "negative polarity items" (Fillmore et al., 1988: 512), some of these markers tend to be used more positively than negatively. Thus, we observe that let alone, not to mention 
and never mind can be used positively to add or highlight a piece of information. In these cases the X part of the construction is not necessarily negative: Finding and keeping a job is hard enough, let alone finding one I love doing ${ }^{8}$; This is one of the best restaurants in the country, never mind Cambridge. This use is not attested in the case of much less or still less. The broader use of let alone, not to mention or never mind stems from the fact that let alone, not to mention and never mind work by singling out the $\mathrm{Y}$ element as adding one or more features to $\mathrm{X}$, which is thus contained in Y. The added features may either contrast with part of $\mathrm{Y}$, as is the case with much less, or they may simply make the meaning of $\mathrm{Y}$ include the meaning of $\mathrm{X}$ thereby making $\mathrm{Y}$ cognitively more prominent. Much less and still less, since they always convey a negative stance, are never used to add more information. This feature of the $X$ Much Less $Y$ and $X$ Still Less $Y$ constructions also explains their tendency to be used in combination with negative if conditionals (If there isn't enough money to buy food, much less/?let alone to buy presents) with preference over its let alone counterpart.

Most of the connectors analysed in this paper can have a positive or negative use, depending on the context where they are inserted. Take the case of X Not To Mention Y, for example; the base of the construction is the same (a complementary alternation) but the construction can have two different profiles:

(i) It can profile an adding relation, where the discourse marker not to mention could be replaced by a connector like and, with an emotive connotation on the speaker's part. When this is the case, the $\mathrm{X}$ and the $\mathrm{Y}$ elements are on an equal footing (as seen from the speaker's perspective): The weather here is gorgeous, not to mention the wonderful food. ${ }^{10}$

(ii) It can profile a contrast relation, where one element is either less or more likely to be the case than the other: I don't think people have the wherewithal, not to mention the inclination, to ramp it $u^{11}$ (i.e. people is less likely to have the wherewithal than the inclination ro ramp it up). In cases like (i) not to mention cannot be replaced by much less, not even when the $\mathrm{X}$ part is explicitly negative. For the cases in (ii), not to mention and much less seem to be interchangeable without apparent differences in meaning.

While the first profile fully equates with its active zone, the second profile, once used within the context of a given expression, can display at least two active zones. In one of them, $\mathrm{Y}$ is less likely than $\mathrm{X}$ (e.g. I don't think people have the wherewithal, not to mention the inclination to ramp it up) and in the other $\mathrm{Y}$ is more likely (e.g. I will always remember this paradise you live in. Not to mention all the great meals at your place! $!^{12}$ ). 
Although this construction might seem to be synonymous with $X$ To Say Nothing of $Y$, there are subtle differences in meaning, which result from the different active zones exploited by each of the constructions in question:

- $\mathrm{X}$ not to mention $\mathrm{Y}: \mathrm{Y}$ is presupposed, so there is no need to talk about it, and Y should be taken for granted.

- $\mathrm{X}$ to say nothing of $\mathrm{Y}$ : $\mathrm{X}$ is (known to be) the case, and $\mathrm{Y}$ is (known to be) specially the case.

This meaning contrast is evidenced by the following examples:

(11) You have a wonderful staff \& service, not to mention the food (Google $\left.{ }^{13}\right)$.

(12) After all, it was the tropical flora and fauna, to say nothing of the sunshine that brought her back to Florida (COCA, 2001).

In (11) the speaker is talking about the relative weight of the main reasons why he goes to a particular restaurant. At the same time, the example presupposes that the quality of the food in that restaurant $(\mathrm{Y})$ is naturally the main reason, any other $(\mathrm{X})$ being secondary. In example (12), on the other hand, the speaker treats as already known the information that the reason why the protagonist decides to go to Florida is first of all the sunshine (Y) and then the flora and fauna (X). The use of the additional discourse marker "after all" is consistent -and underscores- this aspect of the meaning of the construction.

The last construction that will be discussed in this paper is Not X Not Even Y. In this configuration the speaker cancels out an expectation previously generated by him/her or by a third party, namely that the circumstances in $X$ are true. The speaker's utterance expresses an idea that goes against the existing circumstances, re-including an element (the Y part of the construction) that had been previously dissociated from them. In this construction, the $\mathrm{X}$ part is generic, an uncountable NP, which affords access to the more specific Y part. Figure 2 below illustrates this idea of cancelling a previously generated expectation. The bigger circle represents the series of events (in turn represented by the smaller circles) that make up the state of affairs designated by the $\mathrm{X}$ part of the construction. The filled-in crossed-out circle outside stands for $\mathrm{Y}$, i.e. the event that the speaker had previously dissociated from the existing state of affairs. The arrow pointing toward the filled-in circle shows the re-inclusion of this same element back into the meaning area designated by X. Note that the formerly dissociated element was expected to have been the case. The construction underscores the fact that such an expectation was misled from the speaker's point of view. 


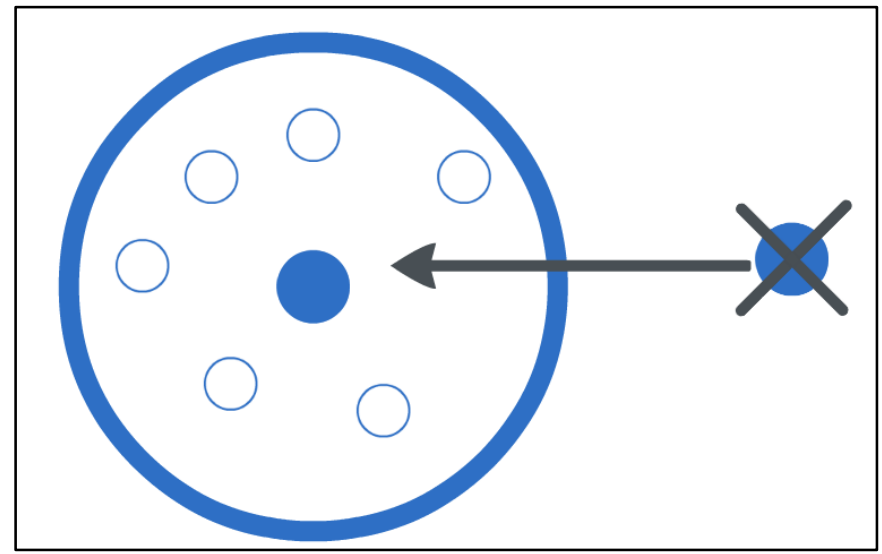

Figure 2. Not X, Not Even Y

The following examples are self-evident in this respect:

(13) a. No one, not even the police department, wanted to go toe-to-toe with Gabby, and that included Chief. (COCA, 2012).

b. Afghanistan had been hidden away and not a single one, not Massoudi, not even the lowest guard who knew about that told anybody that the treasures still existed. (COCA, 2011).

c. From the short jungle came no sound, not even the rustling of leaves. I had experienced few islands in my short existence. (COCA, 2011).

These three examples make use of universally quantified expressions like no one, not a single one, and no sound, which make up the X part of the construction. With the use of not even the speaker (i) presupposes that the addressee, or any third party, holds the erroneous assumption that the specific parts, i.e. the police department in (13a.), the lowest guard in (13b.), and the rustling of leaves in (13c.), are not elements of X, and (ii) he cancels out this assumption.

It is important to notice that it is sometimes possible to use any of the connectors analysed in this paper indistinctively, as we can see in example (14) below, which has been altered to illustrate this point. When this occurs, the difference in active zone has no consequences to block the use of most or all connectors. But each of them always adds a touch of meaning that becomes part of the meaning impact of the construction. On other occasions active zone differences block the use of a connector, as in the case of much less, which is explicitly negative, as explained above.

(14) I cannot afford to build a tool shed, never mind / much less / not to mention / let alone a new house. (WebCorp: http://public.wsu.edu/ brians/errors/letalone.html, 2009-06-20). 
So far, this section has discussed three possible routes to create contrast conditions in the complementary alternation discourse constructions:

- By dissociation.

- By breaking an existing expectation.

- By having two events on a scale of probability and creating an expectation, either by moving up and down the scale of quantity (using more/less) or by considering the time of the event (still less).

These issues were not discussed in Fillmore et al. (1988) when they studied the $X$ Let Alone $Y$ construction. They argued that the construction in question was an example of a paired focus construction. Instead, we contend that rather than two foci, complementary alternation discourse constructions have a focal complex with internal differences in conceptual prominence. For example, in I won't eat that garbage, let alone/much less pay for $i t$, there is a single focal constituent, which is determined by the contrast between eating and buying; both elements have the same status from the point of view of their quality as new (i.e. focal) information, but the second has greater conceptual prominence.

\section{COGNITIVE OPERATIONS}

In this paper we will use the term cognitive operation to designate cognitive activity that contributes to meaning-derivation, as discussed in Ruiz de Mendoza (2011) and Ruiz de Mendoza and Galera (2014). Following this work, we distinguish between formal cognitive operations and content cognitive operations. The former are high-level processes that act as pre-requisites for the latter to be possible. Content operations act on cognitive models (i.e. knowledge constructs such as frames, or meaning structures capturing world knowledge relations among entities, and image schemas or topological constructs arising from the way people interact with the world in terms of visual and motor experience; cf. Lakoff, 1987) thereby giving rise to meaning implications of various kinds. For example, metaphorical correlation between quantity (an abstract magnitude) and height is used in Prices are soaring to refer to a quicker than usual increase in prices. For such correlation to be possible we need to select relevant conceptual structure about market activity and put it into correspondence with selected conceptual structure about upward motion. This selection process is in turn activated by lexical cues that point in the direction of the knowledge schemas that are relevant for the interpretation of the sentence above. In this paper, we will focus our attention on the operations that relate to complementary alternation discourse constructions: highlighting, broadening, contrasting, addition and re-instatement. 
Highlighting and broadening are two cognitive operations commonly found at the processing of conceptual metonymies. In Cognitive Linguistics metonymy is seen as a standsfor relationship between two concepts which belong to the same conceptual framework, where a "source" concept affords access to a related "target" concept. Metonymies whose target is part of the source domain involve highlighting the target with the consequent reduction of the scope of the source domain; this involves cutting down the amount of conceptual material used to construct the meaning interpretation. For example, She eats rabbit refers to rabbit's meat, reducing our knowledge of rabbits to the parts of the animal we eat. In contrast, source-in-target metonymies make use of broadening, which involves domain expansion and consists in increasing the amount of relevant conceptual material on the basis of the point of access provided by the metonymic source (Ruiz de Mendoza, 2011: 106). An example of expansion is the metonymic use of 'hand' in We need more hands to complete the job were a physical hand stands for the workers that would complete the job.

In turn, in contrasting and addition two separate domains are conflated into one single domain. For example, the word Motel, which designates a type of accommodation made close to main roads, combines the concepts of hotels and motorways into a new single concept. In contrasting, this single domain reconciles the existing discrepancies between the domains that were previously separated. In the metaphor My surgeon is a butcher, we contrast/compare the surgeon's delicate task of cutting at the surgery table with the apparently more sloppy way in which a butcher cuts up meat.

These four cognitive operations can take place individually or in combination when they operate in complementary alternation constructions. In this line, we can distinguish between simple cognitive operations and complex cognitive operations or amalgams.

\subsection{Simple cognitive operations}

As could be expected, the most neutral member of the family (the Not X nor $Y$ construction) is characterized by the simplest cognitive behavior, as can be seen from the following example:

(15) European defense is not intended - nor is it able (European Parliament Debates ${ }^{14}$ ).

In this example, the negative idea that the European defense is not intended is complemented with the idea that it is not "able" either. Both are united to create a new concept, that is, the inability of the European defense.

This concept of negative addition can also be observed in the following examples:

(16) a. She can't boil potatoes nor a cabbage.

b. He isn't clever nor rich.

c. Not I, nor anyone else can travel that road for you. (Walt Whitman, Leaves of Grass). 
It must be noted that, in some contexts, examples (16a.) and (16b.) could also involve broadening. In (16a) the protagonist is explicitly treated as unable to boil potatoes and cabbages. Since directly boiling vegetables is a very simple task, this sentence could imply that the protagonist is unable to cook anything. In a similar vein, (16b) could imply that the protagonist is worthless given the central role that Western society gives to being clever and rich.

\subsection{Complex cognitive operations or amalgams}

Most of the members of the constructional family that are the object of this study work by combining two cognitive operations, thereby forming an amalgam of cognitive operations. Such an amalgam determines the profile of the complementary alternation relation.

The first amalgam is the one formed by combining the cognitive operations of highlighting (sometimes resulting in a domain reduction) and contrasting. The connectors still less, much less, not even, let alone, never mind and to say nothing of exploit this kind of amalgam of cognitive operations. This combination results in the common ultimate meaning 'Y-is-certainly-not-the-case.' For example, in the sentence I never suggested he was incompetent, still less dishonest (Merriam Webster Dictionary Online), the speaker contrasts the idea of being incompetent with the idea of being dishonest (see Figure 3 below). The speaker understands the hypothetical situation where he would have said that the person in question was dishonest as being worse than saying he was incompetent, thereby highlighting this negative feature over the idea of being incompetent.

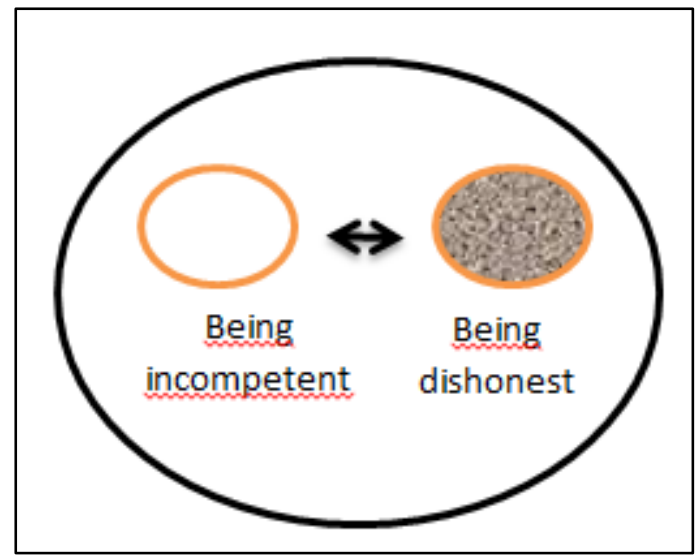

Figure 3. Highlighting + contrast WITHOUT domain reduction:

I never suggested he was incompetent, still less dishonest

This is also observable in example (6) above, repeated here as (17) for the reader's convenience:

(17) The object is not to work hard, still less to make yourself miserable. The object is to get the work done (COCA, 1996). 
In this sentence the speaker explains that the object of the situation is simply "to get the work done". The sentence opposes the idea of working hard, seen as a negative situation from the speaker's perspective, to the idea of becoming miserable, which is perceived as even worse. In an imaginary scale of what is acceptable or not for the given situation, working hard would be below getting the work done, and becoming miserable would be even lower on the same scale. The speaker understands the hypothetical situation of becoming miserable as a worse scenario than working hard, thereby highlighting this negative feature resulting in the common ultimate meaning 'being miserable-is-certainly-not-the-object.'

The sentence Because we are the first foreigners, let alone journalists that the Doctors Without Borders street team had ever taken with them (COCA, 2012) shows the same highlighting + contrast amalgam, but in this case highlighting results in domain reduction, as the element 'first foreign journalists' is included in the 'first foreign people' domain (see Figure 4 below).

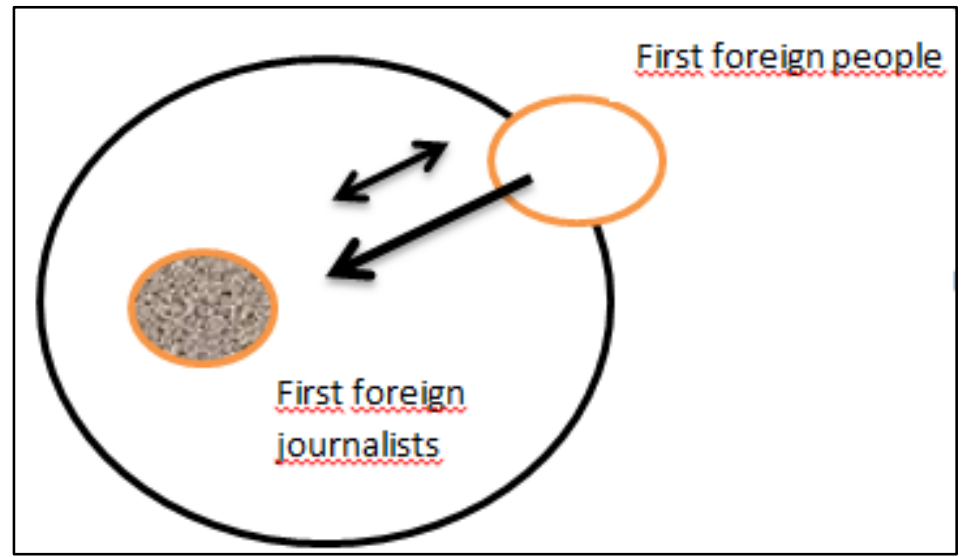

Figure 4. Highlighting + contrast WITH domain reduction

A second type of amalgam is based on the combination of the cognitive operations of highlighting and adding (see Figure 5 below). In these cases, the elements in the Y part of the construction do not contrast with the elements in $\mathrm{X}$, but are added to the information contained in $\mathrm{X}$. The profile of the constructions that belong to this second type of amalgam is that ' $\mathrm{Y}$ is certainly the case', the routes to access the same meaning corresponding to each of the active zones of the constructions $X$ Not To Mention $Y, X$ Never Mind $Y, X$ Let Alone $Y$ and $X$ To Say Nothing of $Y$. 


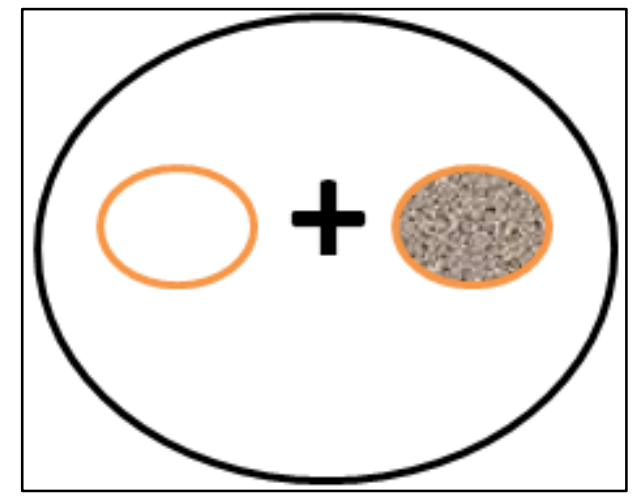

Figure 5. Highlighting + addition amalgam

Examples like the following (used above and repeated here for the reader's convenience) are evidence of this type of cognitive behavior:

(18) a. You have a wonderful staff and service, not to mention the food. (WebCorp: http://www.matakanamarketkitchen.co.nz/about-us/reviews.aspx, 2011-01-01).

b. With this knee I can hardly walk, never mind run. (Merriam Webster Dictionary Online).

In (18a) the speaker praises a restaurant describing the professionalism of its employees and the food served in it to give account of its quality or to recommend it to a third party. In this case, the staff and the food do not contrast with each other but are both summed up (i.e. added) to conform the idea of a successful 'dining out' experience. The addition process is complemented with greater focus on the part of the expression introduced by the connector, in such a way that the quality of the food in this example is given prominence over the efficacy of the staff and service. The same rationale applies to (18b), where the problems with the speaker's knee disables the speaker from both walking and (logically) running, while running is emphasized.

The last amalgam that uses highlighting is the one resulting from the combination of highlighting and re-instatement. In the sentence No one in the Bureau could offer any such proof, not even the chaplain, who on more than one occasion had been reduced to muttering (COCA, 2012) 'not even the chaplain' presumes that the addressee could erroneously believe that the chaplain is an exception. In this way, the function of the 'not even' part of the construction is to re-instate the chaplain into the set of all people that could not offer any proof.

The fourth type of amalgam is formed by combining the broadening and contrast cognitive operations. The constructions $X$ Much Less $Y, X$ Never Mind $Y$, X Let Alone $Y$ and $X$ To Say Nothing of $Y$ respond to this type of cognitive operation.

Consider again the example (8) in the previous section, which we repeat as (19): 
(19) But you cannot teach 400 students at a time, much less 100,000.

In (19), the image of having an amount of students in a class is broadened to include even more students in the same class. A contrast is thus created between what it means to teach 400 students (the $\mathrm{X}$ element) and the broadened Y element (100,000 students) (see Figure 6 below).

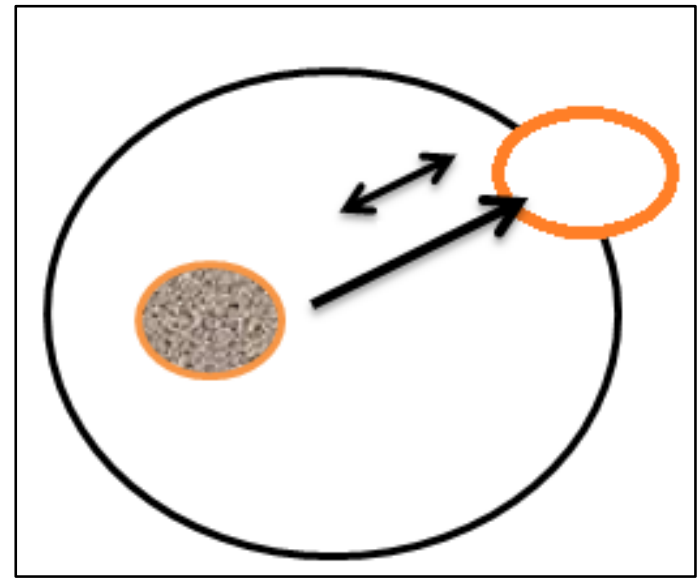

Figure 6. Broadening + contrast amalgam

The last amalgam corresponds to the combination of the broadening and addition cognitive operations. In these cases the profile of the construction is that ' $\mathrm{Y}$ is less probable to happen than $\mathrm{X}, \mathrm{Y}$ belonging to a wider domain than $\mathrm{X}$ '. This type of amalgam explains the impossibility of sentences like *I can't afford to build a new house, never mind a tool shed. A tool shed is more insignificant than a house, so its canonical place in the construction should be in the X part. The correct form of the utterance would be example (14), repeated as (20) below for the reader's convenience:

(20) I can't afford to build a tool shed, never mind a new house.

In (20) building a new house, which is less probable than building a new shed, involves a bigger enterprise thus setting up a broader domain in terms of the difficulty (and cost) of the task. This interpretation is consonant with the rationale for expressions like He can't boil potatoes, much less/never mind cook the whole meal! (Word Web Online Dictionary): if the person in question is unable to do the simplest tasks in the preparation of the meal (i.e. boiling the potatoes), he/she will certainly be unable to perform the difficult task of cooking the whole meal without help (see Figure 7). 


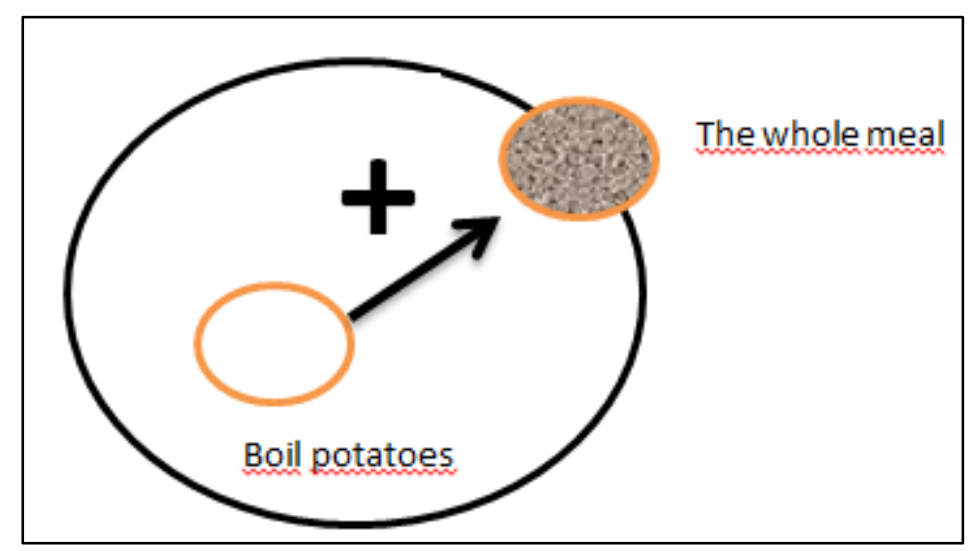

Figure 7. Broadening + adding amalgam

In sum, in complementary alternation discourse constructions we find two types of cognitive operations at work: simple cognitive operations (negative addition and/or reassociation) and operation amalgams. In this latter situation, we have classified the amalgams into cases of:
1) Highlighting (with and without domain reduction) + contrasting
2) Highlighting + adding
3) Highlighting + re-instatement
4) Broadening + contrasting
5) Broadening + adding

\section{CONCLUSION}

This paper has argued that the different constructions that profile the same base domain are members of the same constructional family. For this reason the constructions dealt with herein belong to a subgroup within the same constructional family, which has been labeled the family of complementary alternation discourse constructions. In this group of constructions, $\mathrm{X}$ and $\mathrm{Y}$ are two situations such that $\mathrm{Y}$ is less likely (or more likely) to happen than $\mathrm{X}$. Each member of the group (X Let Alone $Y, X$ Much Less $Y, X$ Never Mind $Y, X$ Not To Mention $Y$, Not X Nor Y, X Still Less Y, Not X Not Even Y, and X To Say Nothing of $Y$ ) introduces subtle changes in focal structure, resulting in changes on the overall coherence of the text. The way in which the $\mathrm{X}$ and the $\mathrm{Y}$ element relate is the active zone of the construction, the volume of features that situate $\mathrm{Y}$ in a worse (or better) situation than $\mathrm{X}$. Based on these theoretical explanations, the paper has specified the conditions for the use of one connector with preference over the others.

The treatment of these constructions as a family has allowed us to fully motivate their meaning and realizational behavior. This involves an advantage over previous analyses of 
constructional characterizations typically based on just one construction, as is the case with the well-known study of let alone by Fillmore et al. (1998) or other studies like Bender and Kathol (2001) on Just Because X Doesn't Mean Y, and Kay and Fillmore's (1999) work on What's $X$ Doing $Y$. We have also avoided another analytical problem from previous work on what we label discourse constructions, i.e. the error in postulating the existence of two foci, as proposed by Fillmore et al. (1988), for the let alone construction. The constructions studied in this paper have a focal complex with internal differences in conceptual prominence. This explanation avoids the pitfall of confusing focal information (or new information, by way of contrast with topical information) with highlighted (or conceptually prominent) elements within a focal constituent.

Finally, section 4 has argued that complementary alternation distinctions revolve around the notions of addition and contrast. This section has also revealed that in the case of complementary alternation discourse connectors it is possible to find contrast and addition cognitive operations in combination with the operations of highlighting, re-instatement and broadening, thereby resulting in amalgams of cognitive operations.

\section{ACKNOWLEDGEMENTS}

The author would like to express her appreciation to professors Geoffrey K. Pullum (University of Edinburgh) and Lachlan Mackenzie (VU University Amsterdam) for their encouraging comments on a preliminary version of this paper presented at the Second International Workshop on Discourse Analysis (Santiago de Compostela, 2013). Special thanks go to professor Francisco Ruiz de Mendoza (University of La Rioja) for his many helpful remarks on a preliminary draft of this manuscript. Of course, any remaining flaws are my own responsibility.

\section{NOTES}

1. The research on which this paper is based has received financial support from the Spanish Ministry of Economy and Competitiveness, grants No. FFI 2010-17610/FILO and FFI201343593-P.

2. The dictionaries consulted were the Collins Cobuild English Dictionary (1990), the Cambridge Dictionaries Online (http://dictionary.cambridge.org/) and the Merriam Webster Dictionary Online (http://www.m-w.com/dictionary), among others.

3. The cognitive validity of the notion of construction has been strongly supported by empirical psycholinguistic research (e.g. Bencini \& Goldberg, 2000; Goldberg \& Bencini, 2005; Eddington \& Ruiz de Mendoza, 2010).

4. Example extracted from WebCorp: WebCorp: http://www.telegraph.co.uk/sport/football/teams/newcastle-united/2670409/Kevin-Keegan-hasnot-resigned-but-talks-with-Newcastle-board-continue-say-LMA-Football.html (2008-09-02).

5. Mairal Usón, R. \& Ruiz de Mendoza, F.J. (2009: 29).

6. Example extracted from WebCorp: WebCorp: http://www.whydev.org/how-do-you-change-theway-australians-think-about-poverty-let-alone-extreme-poverty/ (date unknown).

7. Example extracted from WebCorp: https://plus.google.com/RichardBranson/posts/cNtGG9tSWUp (date unknown)

8. Example extracted from WebCorp: https://plus.google.com/RichardBranson/posts/cNtGG9tSWUp (date unknown). 
9. Example extracted from Cambridge Dictionary Online.

10. Example extracted from the Macmillan Dictionary Online.

11. Example extracted from WebCorp: http://www.democraticunderground.com/1014869781 (2014-01-01)

12. Example extracted from Google: www.hawaiilifestyles.net/guests-comments.html (last accessed 18/09/2014, 13:11)

13. http://www.matakanamarketkitchen.co.nz/about-us/reviews.aspx (last accessed 26/12/2013, $12: 21)$

14. http://www.europarl.europa.eu/sides/getDoc.do?pubRef=-//EP//TEXT+CRE+20020409+ITEM$007+\mathrm{DOC}+\mathrm{XML}+\mathrm{V} 0 / / \mathrm{EN} \&$ query $=\mathrm{INTERV} \&$ detail $=2-166$

\section{REFERENCES}

Baicchi, A. (2011). Metaphoric motivation in grammatical structure: The caused-motion construction from the perspective of the Lexical-Constructional Model. In K.-U. Panther \& G. Radden (Eds.), Motivation in Grammar and the Lexicon (pp. 149-170). Amsterdam/Philadelphia: John Benjamins.

Baicchi, A. \& Ruiz de Mendoza, F. J. (2010). The cognitive grounding of illocutionary constructions within the theoretical perspective of the Lexical-Constructional Model. Textus: English Studies in Italy 23(3), 543-563.

Bencini, G. \& Goldberg, A. (2000). The contribution of argument structure constructions to sentence meaning. Journal of Memory and Language, 43, 640-651.

Bender, E. M. \& Kathol, A. (2001). Constructional Effects of Just Because ... Doesn't Mean ... BLS, $27,13-25$.

Butler, C. S. (2009). The Lexical Constructional Model: Genesis, strengths and challenges. In C. S. Butler \& J. M. Arista (Eds.), Deconstructing Constructions (pp. 117-152). Amsterdam/ Philadelphia: John Benjamins.

Butler, C. S. (2013). Constructions in the Lexical Constructional Model. In E. Diedrichsen, E. \& B. Nolan (Eds.), Linking Constructions into Functional Linguistics: The Role of Constructions in $R R G$ Grammars (Studies in Language Series) (pp. 271-294). Amsterdam/Philadelphia: John Benjamins.

Collins Cobuild English Language Dictionary. (1990). London: Collins.

Del Campo, N. (2011). Cognitive modelling in illocutionary meaning. Review of Cognitive Linguistics, 9(2), 392-412.

Del Campo, N. (2013). Illocutionary Constructions in English: Cognitive Motivation and Linguistic Realization. Bern: Peter Lang.

Eddington, D. \& Ruiz de Mendoza, F.J. (2010). Argument constructions and language processing: Evidence from a priming experiment and pedagogical implications. In S. De Knop, F. Boers \& T. De Rycker (Eds.), Fostering Language Teaching Efficiency through Cognitive Linguistics (pp. 213-238). Berlin \& New York: Mouton de Gruyter.

Fillmore, C., P. Kay, P. \& O'Connor, C. (1988). Regularity and idiomaticity in grammatical constructions: The case of let alone. Language 64, 501-538.

Galera, A. \& Ruiz de Mendoza, F. J. (2012). Lexical class and perspectivization constraints on subsumption in the Lexical Constructional Model: The case of say verbs in English. Language Sciences, 34, 54-64.

Gibbs, R. W. (2006). Embodiment and Cognitive Science. New York: Cambridge University Press.

Gibbs, R. W. (2011). Evaluating conceptual metaphor theory. Discourse Processes, 48(8), 529-562.

Goldberg, A. (1995). Constructions: A Construction Grammar Approach to Argument Structure. Chicago: University of Chicago Press.

Goldberg, A. (1998). Patterns of experience in patterns of language. In M. Tomasello (Ed.), The New Psychology of Language. Vol. 1 (pp. 203-219). Mahwah, N. J.: Lawrence Erlbaum.

Goldberg, A. (2006). Constructions at Work. The Nature of Generalization in Language. Oxford: Oxford University Press. 
Goldberg A. \& Bencini, G. M. L. (2005). Support from processing for a constructional approach to grammar. In A. Tyler, M. Takada, Y. Kim \& D. Marinova (Eds.), Language in Use: Cognitive and Discourse Perspectives on Language and Language Learning (pp. 3-18). Washington DC: Georgetown University Press.

Goldberg, A. \& Jackendoff, R. (2004). The English resultative as a family of constructions. Language, $80(3), 532-568$.

Gonzálvez-García, F. (2009). The family of object-related depictives in English and Spanish: Towards a usage-based, constructionist analysis. Language Sciences, 31(5), 663-723.

Gonzálvez-García, F. (2012). Metaphor and metonymy do not render coercion superfluous: Evidence from the subjective-transitive construction. Linguistics, 49(6), 1305-1358.

Kay P. (2002). An informal sketch of a formal architecture for Construction Grammar. Grammars, 5, $1-19$.

Kay, P. \& Fillmore, C. J. (1999). Grammatical constructions and linguistic generalizations: The What's X doing Y? construction. Language, 75(1), 1-33.

Lakoff, G. (1987). Women, fire, and dangerous things: What categories reveal about the mind. Chicago: University of Chicago Press.

Lakoff, G. \& Johnson, M. (1999). Philosophy in the Flesh. New York: Basic Books.

Langacker, R. W. (1987). Foundations of Cognitive Grammar. Vol. 1: Theoretical Prerequisites; Vol. 2: Descriptive Application. Stanford, CA: Stanford University Press.

Langacker, R. W. (1999). Grammar and Conceptualization. Berlin \& New York: Mouton de Gruyter.

Langacker, R.W. (2005). Construction Grammars: Cognitive, radical and less so. In F. J. Ruiz de Mendoza Ibáñez \& S. Peña Cervel (Eds.), Cognitive Linguistics: Internal dynamics and interdisciplinary interaction (pp. 101-159). Berlin / New York: Mouton de Gruyter.

Mairal Usón, R. \& Ruiz de Mendoza, F.J. (2009). Levels of description and explanation in meaning construction. In Ch. Butler \& J. Martín Arista (Eds.) Deconstructing Constructions (pp. 153198). Amsterdam / Philadelphia: John Benjamins.

Peña, S. (2009). Constraints on subsumption in the caused-motion construction. Language Sciences, 31, 740-765.

Pérez, L. \& Ruiz de Mendoza, F. J. (2011). A Lexical-Constructional Model account of illocution. Vigo International Journal of Applied Linguistics 8, 99-138.

Ruiz de Mendoza, F. J. (2011). Metonymy and cognitive operations. In R. Benczes, A. Barcelona, \& F. J. Ruiz de Mendoza (Eds.), Defining Metonymy in Cognitive Linguistics. Towards a consensus view (pp. 103-123). Amsterdam / Philadelphia: John Benjamins.

Ruiz de Mendoza, F. J. (2013). Meaning construction, meaning interpretation and formal expression in the Lexical Constructional Model. In E. Diedrichsen \& B. Nolan (Eds.), Linking Constructions into Functional Linguistics: The Role of Constructions in RRG Grammars (pp. 231-270). Amsterdam / Philadelphia: John Benjamins.

Ruiz de Mendoza, F. J. (2014). Mapping concepts: Understanding figurative thought from a cognitivelinguistic perspective. Spanish Journal of Applied Linguistics 27(1), 187-207.

Ruiz de Mendoza, F. J. \& Baicchi, A. (2007). Illocutionary constructions: Cognitive motivation and linguistic realization. In I. Kecskes \& L. Horn (Eds.), Explorations in Pragmatics: Linguistic, Cognitive, and Intercultural Aspects (pp. 95-128). Berlin/New York: Mouton de Gruyter.

Ruiz de Mendoza, F. J. \& Galera, A. (2014). Cognitive Modeling. A Linguistic Perspective. Amsterdam / Philadelphia: John Benjamins.

Ruiz de Mendoza, F. J. \& Gómez González, M.A. (2014). Constructing discourse and discourse constructions. In Gómez González, M. A., Ruiz de Mendoza Ibáñez, F. J., Gonzálvez-García, F., Downing, A. (Eds.), Theory and Practice in Functional-Cognitive Space (295-314). Amsterdam / Philadelphia: John Benjamins.

Ruiz de Mendoza, F. J. \& Gonzálvez-García, F. (2011). Constructional integration in the Lexical Constructional Model. British and American Studies, 17, 75-95.

Ruiz de Mendoza, F. J. \& Mairal Usón, R. (2008). Levels of description and constraining factors in meaning construction: An introduction to the Lexical Constructional Model. Folia Linguistica Acta Societatis Linguisticae Europaea, 42(2), 355-400.

Ruiz de Mendoza, F. J. \& Mairal Usón, R. (2011). Constraints on syntactic alternation: Lexicalconstructional subsumption in the Lexical Constructional Model. In P. Guerrero (Ed.), 
Morphosyntactic Alternations in English: Functional and Cognitive Perspectives (pp. 62-82). Equinox Publishing Books.

Taylor, J. (1995). Linguistic categorization. (2nd ed.). Oxford: Oxford University Press. 